\title{
Three-Dimensional Surface Imaging and the Continuous Evolution of Preoperative and Postoperative Assessment in Rhinoplasty
}

\author{
Garyfalia Lekakis, MD, FRCS (ORL-HNS) ${ }^{1}$ Peter Claes, PhD ${ }^{2}$ Grant S. Hamilton III, MD, FACS 3 \\ P. W. Hellings, MD, PhD ${ }^{1}$ \\ ${ }^{1}$ Department of ENT, University Hospitals Leuven, Leuven, Belgium \\ ${ }^{2}$ Department of Electrical Engineering, Medical Image Computing, \\ Leuven, Belgium \\ ${ }^{3}$ Division of Facial Plastic and Reconstructive Surgery, Department of \\ Address for correspondence Garyfalia Lekakis, MD, FRCS (ORL-HNS), \\ Department of ENT, University Hospitals Leuven, St Rafael Campus, \\ Kapucijnenvoer 33, Leuven 3000, Belgium \\ (e-mail: philio.lekakis@gmail.com).
}

Otorhinolaryngology, Mayo Clinic, Rochester, Minnesota

Facial Plast Surg 2016;32:88-94.

\begin{abstract}
Keywords

- three-dimensional surface imaging

- rhinoplasty

- preoperative planning

- facial analysis

- postoperative assessment

During the preoperative assessment in rhinoplasty, the surgeon takes a thorough history, performs a complete examination by assessing functional and aesthetic aspects of the nose, obtains a clear understanding of the patient's wishes, conducts facial analysis based on standardized photography, and communicates to the patient the goals and pitfalls of surgery. Computer imaging or morphing of the preoperative pictures of the nose has drawn a lot of interest in the last decade, and it is a sign of evolution of the preoperative consultation. Technological advances, also in the context of rhinoplasty, have led to the development of three-dimensional (3D) imaging techniques, and have completely revolutionized the way that surgeons manage their patients preoperatively and evaluate postoperative results today. The accurate 3D surface imaging aids the surgeon to communicate with the patient adequately before surgery, to set an appropriate surgical plan, and to measure the shape and volume changes of the patient's nose that result from the intervention. The present review provides an analysis on the current knowledge of 3D surface imaging in rhinoplasty derived from the literature, and highlights future directions of preoperative and postoperative assessment in the field.
\end{abstract}

Success in rhinoplasty dictates a satisfied patient with a good functional and aesthetic result. Given the central location of the nose in the face, the complexity of improving both aesthetics and function, and the unpredictability of healing following rhinoplasty, all efforts during pre-, peri-, and postoperative stages should concentrate on patient's satisfaction. Based on standard views of the nose (frontal, lateral, three-quarter, and basal), analyses for purposes of preoperative planning and postoperative evaluation are routinely performed in the clinic before and after rhinoplasty. However, there are certain inadequacies that arise from the fact that a three-dimensional (3D) structure like the nose is depicted on a $2 \mathrm{D}$ image.
With advances in technology that have led to the use of 3D surface imaging techniques, it is now feasible to overcome these shortcomings. There are several different types of 3D surface imaging modalities developed. Nowadays, due to their fast acquisition time and ease of use, both 3D digital stereophotogrammetry (using two or more photographs from slightly different vantage points to calculate the 3D shape of an object) and structured light technology (projecting a standardized pattern of light on an object and analyzing the distortion to record the 3D surface contour) are becoming the preferred facial surface imaging techniques in hospitals and research centers. Given the accuracy and reliability of these
Issue Theme Functional Rhinoplasty; Guest Editor, Grant S. Hamilton III, MD, FACS
Copyright @ 2016 by Thieme Medical Publishers, Inc., 333 Seventh Avenue, New York, NY 10001, USA. Tel: +1(212) 584-4662.
DOI http://dx.doi.org/ 10.1055/s-0035-1570122. ISSN $0736-6825$. 
systems, validated by several articles, their use for clinical research is becoming increasingly important.

Such systems can serve as an exceptional tool for the rhinoplasty surgeon, as they have the potential to enhance clinical care by ameliorating preoperative evaluation, facilitating surgical planning, and improving outcome assessment.

\section{Evolution of Imaging from 2D to 3D}

By peering over the archives of facial plastic surgery, it emerges that conventional objective assessment methods to evaluate the nose and the face preoperatively have been based on 2D facial analysis with techniques such as cephalometry, anthropometry, or photogrammetry. ${ }^{1-3}$ Cephalometric radiographs, usually in the midsagittal plane, do not allow for detailed soft tissue analysis. ${ }^{4}$ Traditional anthropometry using measuring devices is hindered by the amount of time involved. Photogrammetry (making measurements on a photograph created at a known scale) has been for half a century the ideal instrument for facial analysis. Despite the limitations produced by changes in lighting or position and lens distortion, advances in digital photography and imaging have made it a universal method of facial analysis and evaluation in rhinoplasty. For a long time, 2D techniques were the only techniques available to acquire measurements of 3D objects like the nose or the face. Routinely, preoperative facial analysis is performed and postoperative results are evaluated by measuring distances, angles, and ratios over the standardized views obtained before and after rhinoplasty. These views are well known and have been described in detail. ${ }^{5}$ Several articles, however, have focused on the principles of photography, as correct execution of these standard views is imperative to critically evaluate the nasal anatomy. ${ }^{6}$ Several authors have also highlighted the limitations and pitfalls of photography for facial topography ${ }^{7,8}$ in relation to rhinoplasty or other facial plastic surgery procedures. Twodimensional photography often introduces inaccurate measurements related to lack of standardization in equipment, variability in head position, or changes in magnification from setting to setting. Above all, 2D techniques dictate that the surgeons formulate a mental image of the nose and the face out of 2D data. Creating an accurate 3D mental model from a series of $2 \mathrm{D}$ photos can be challenging, even for an experienced rhinoplasty surgeon. Other authors have also commented on the inability to address facial depth and nasal shape when representing the face or the nose in a 2D image, ${ }^{9}$ leading to loss of data as well as the failure to account for differences in depth, symmetry, and shape. ${ }^{10}$ Additionally, the limitations of a 2D medium significantly reduce the ability to objectively quantify treatment results for patients.

These drawbacks, and the need for minimizing subjectivity when quantifying the effects of surgery, have pushed the borders of capturing facial topography to a new 3D era. Although 3D imaging has been used in computer animation, anthropometry, and dentistry for some time, its use in medicine is more contemporary and is already having a significant impact. ${ }^{11}$ Recent advances in technology have generated a variety of 3D modalities. They include 3D ultrasonography, Moiré topography, digital stereophotogrammetry, 3D computed tomography, laser surface scanning, and structured light technology. According to Honrado and Larrabee, ${ }^{11}$ the availability of 3D imaging and software systems presents new opportunities for the facial plastic surgeon on how to plan, execute, and assess outcomes in patients undergoing surgery of the face and neck.

\section{History of Development of 3D Surface Imaging Systems}

Earlier efforts to image the intricacies of the anatomy of the face in 3D include 3D cephalometry, 3D ultrasonography, 3D computed tomography, Moiré topography, stereophotogrammetry, structured light technology, and laser scanning. Some of these technologies require expensive equipment, and the ability to determine soft tissue features is limited. Subsequently, only a few of these modalities provided 3D measurements with promising results. ${ }^{12}$

Three-dimensional cephalometry relied on manual techniques to abstract 3D coordinates from lateral and anteroposterior radiographs. ${ }^{13}$ Yet, this work was time consuming, soft tissue contour could not be assessed, and patients were exposed to radiation. ${ }^{11}$

Three-dimensional ultrasonography requires a contact probe to generate 3D coordinates. ${ }^{14}$ Pressure of the probe on the soft tissues results in distortion of the image, making this application not clinically useful in facial plastic surgery.

Radiation exposure to the patient as well as image artifacts arising from metal objects in the oral cavity is recognized as the major weaknesses of 3D computed tomography imaging, rendering this application not popular in facial plastic surgery for purposes of aesthetic nasal analysis. ${ }^{11}$

Laser-based surface imaging works on the principle of laser triangulation, as stereophotogrammetry. The 3D scanner emits a laser stripe, which sweeps across the object to be scanned. A camera records data points along the length of strip to create a point cloud of geometric samples on the surface of the subject. ${ }^{15}$ Main limitations remain cost, the inability to capture soft tissue texture, and time for image acquisition, which can be as long as 20 seconds depending on the product, making distortion highly likely especially in children. ${ }^{16}$ The patients eyes must also be closed for protection. $^{11}$

As computer technology and speed advanced exponentially over the past 25 years, optical-based surface imaging technologies have evolved enough to find a more prominent place in the medical field and are currently the most promising methods of 3D surface imaging. Optical-based 3D surface imaging technologies are available to noninvasively capture anatomically precise 3D facial images of the patient. They include structured light imaging, Moiré fringe projection, and stereophotogrammetry imaging systems.

Moiré topography is a technique that has been reported to be extremely time consuming ${ }^{17}$ and requires careful control of lighting that limits the application of this methodology to laboratory conditions. ${ }^{18}$ 
Structured light technology is a technique during which structured light patterns of white light, such as grids dots or stripes, are projected onto the subject. Next, a single image of the subject and the projected pattern are acquired by a digital camera, within the system, calibrated with the specifics of the projected light pattern. The distortion of the light pattern is captured and processed by the system's software to generate the shape data and register appropriate color and texture information. ${ }^{19}$

Stereophotogrammetry is a technique that was first described in $1967 . .^{20}$ This technique differs from the other optics-based methods in that it requires no special pattern projection. The subject can be illuminated with regular photographic flash. This permits rapid image acquisition with no danger to the patient from radiation or lasers. In principle, two pictures are taken of the same object to create a stereo pair and at the same time record depth to generate a composite 3D model. The recorded pattern provides the stereo algorithms to build accurate 3D geometry. Once the 3D geometry model has been built, software maps the color and texture information onto the model. Two basic triangulation strategies exist for stereophotogrammetry: active and passive. Active stereophotogrammetry utilizes the projection of a random unstructured light pattern on the surface of the target object. It combines this pattern with the visible natural pattern of the object's surface to give the stereo algorithms as much information as possible to generate a quality 3D geometry. In contrast, passive stereophotogrammetry generates 3D geometry solely based on the natural patterns of the target object's surface. Multiple cameras at different locations are utilized to triangulate the shape of the object. Multiple synchronous photographs are taken from different angles, which are then digitally merged to produce a 3D image. When a handheld system is used, three different photographs are captured to the camera's SD memory card ( - Fig. 1). The accuracy of these newly developed 3D imaging systems in recording facial morphologic features has been recently validated. ${ }^{21-24}$

The advantages of 3D photogrammetry are near-instantaneous image capture $(1.5 \mathrm{~ms})$ which minimizes motion artifact, provision of archived image for repeated analysis,

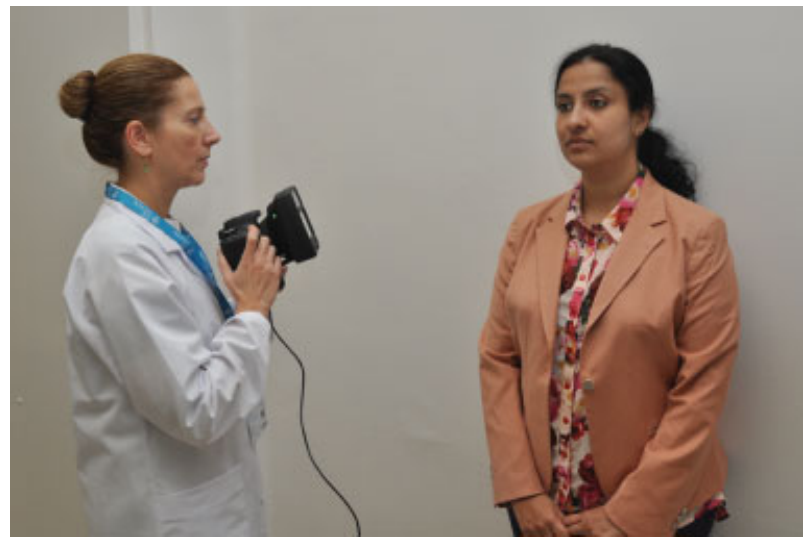

Fig. 1 Handheld system (VECTRA H1) is utilized to obtain 3D images of the face as part of the preoperative assessment for rhinoplasty.

collection of data points in 3D format for subsequent studies, and high-resolution color representation. ${ }^{24}$ Various commercial products using principles of stereophotogrammetry or structure light technology have been developed to generate 3D images and are currently available for purchase and clinical use ( $\mathbf{- T a b l e ~} \mathbf{1})$.

\section{Advantages of 3D Surface Imaging}

\section{D Surface Imaging: Preoperative Assessment- Patients' Perspective}

Patient education is an integral part of the preoperative assessment in rhinoplasty. Three-dimensional images offer the opportunity to patients to view themselves from a different perspective than that offered by a mirror, for example. This advantage makes surface imaging an excellent patient teaching tool. When patients are having their own 3D image viewed at any angle and direction, they get familiar with their own anatomy and possible asymmetries or deformities. This technology also provides a 3D image that can be manipulated for viewing at any angle or direction allowing patients to come face to face with their potential postoperative result. During this stage, discussing the images and setting appropriate expectations will also help patients

Table 1 3D surface imaging systems

\begin{tabular}{|l|l|l|l|}
\hline Company & Equipment & Technology & Software \\
\hline 3dMD (Atlanta, GA) & 3dMD Face System & $\begin{array}{l}\text { Active and passive } \\
\text { stereophotogrammetry }\end{array}$ & 3dMD Vultus \\
\hline Axis Three (Belfast, Ireland) & Axis Three's Face System & $\begin{array}{l}\text { Structured light } \\
\text { CCT: color-coded } \\
\text { triangulation by Siemens }\end{array}$ & Tissue Behavior Simulation \\
\hline $\begin{array}{l}\text { Canfield Scientific } \\
\text { (Fairfield, NJ) }\end{array}$ & Vectra 3D Imaging System & $\begin{array}{l}\text { Passive } \\
\text { stereophotogrammetry }\end{array}$ & $\begin{array}{l}\text { Mirror Imaging Vectra 3D } \\
\text { Sculptor }\end{array}$ \\
\hline Di3D (Glasgow, UK) & $\begin{array}{l}\text { Di3D 3D surface capture } \\
\text { system }\end{array}$ & $\begin{array}{l}\text { Passive } \\
\text { stereophotogrammetry }\end{array}$ & Di3Dview \\
\hline Technest/Genex & 3D Facecam Capture System & Structured light technology & 3D Surgeon \\
\hline
\end{tabular}


understand the goals of treatment. Above all else, utilizing this technology may help patients have confidence in their surgeon and empowered to make an informed decision to have surgery. It is already stated in the literature that computer-aided technologies lead to a higher number of patients deciding to undergo rhinoplasty. ${ }^{25}$

\section{D Surface Imaging: Preoperative Assessment- Surgeons' Perspective}

The preoperative counselling for rhinoplasty remains as important as the procedure itself. ${ }^{26}$ During the preoperative consultation, communicating clearly the goals of surgery and identifying the patient's expectations is an undertaking facilitated by the use of computer imaging. ${ }^{27}$ However, as surgical techniques for rhinoplasty evolve and patients' demands and expectations rise, clinicians are in need for new and more powerful tools. Three-dimensional medical photography is instrumental in providing surgeons with important anatomical information that serves as a foundation for assessment, communication, quantification, and comparison. Honrado and Larrabee ${ }^{11}$ recognized that 3D surface imaging allows the surgeon a thorough evaluation for purposes of facial analysis and assists surgical planning. Facial analysis is of upmost importance as it marks the beginning of a good rhinoplasty result. Three-dimensional tools allow 3D facial analysis in a way that is more meaningful to the surgeons and permit increased insight and understanding of the patient's anatomy. Better appreciation of the individualized anatomical structures and improved understanding of complex underlying conditions will only allow for more meticulous and accurate preoperative planning. ${ }^{28}$ Rhinoplasty is a patientspecific operation, and the ability to capture images in 3D has opened up new avenues for patient-specific tailored treatment. As emphasized before, performing surgical planning in 3D can be invaluable, making surgeons more efficient, surgery safer, and anesthesia shorter. ${ }^{29}$

\section{D Surface Imaging: Preoperative Assessment- Rapport}

Three-dimensional surface images offer some exceptional views and by doing so take the surgeon to a new more interactive level of communication with the patient. Photographing the patients using 3D technology and analyzing these images with respect to the patient individual morphology and wishes results in a realistic discussion of the potential outcome and creates a harmonious doctor-patient relationship. This practice facilitates the preoperative consultation, enhances education about rhinoplasty, and contributes to the circumstances within which a good rapport can be established between surgeons and patients.

\section{D Surface Imaging: Postoperative Assessment: Patients' Perspective}

The rapid emergence of 3D surface imaging systems enables a close linkage between photography and patient care. When comparing patients' pretreatment and posttreatment images in two dimensions, comparisons for the benefits of volumetric changes are hindered. However, 3D imaging techniques allow the absolute values of the volume of the preoperative and the postoperative nose to be obtained, for any part of the nose. Subsequently, in superimposed midsagittal plane extractions, changes in nasal length and dorsal height can easily be appreciated by the patients. Chen et al argue that $3 \mathrm{D}$ photography serves as a novel technique to demonstrate results to patients, as it offers the ability to rotate images on all axes, a distinct advantage over $2 \mathrm{D}$ imaging. ${ }^{30}$ The ability of image rotation represents an advantage not only in discussions with patients, but also in scientific research. Increasingly, 3D imaging is becoming the ideal tool for analyzing nasal morphology as determined by important factors such as contour and volume, rendering consultations with patients educational, and assessment of results accurate.

\section{D Imaging: Postoperative Assessment-Surgeons' Perspective}

Historically, outcome measures in rhinoplasty and facial plastic surgery were qualitative and related to patient quality of life and satisfaction, as these areas were believed to be the most important measures of success. ${ }^{31}$ In spite of the fact that these measures were patient centered, they remained subjective. While all aesthetic procedures need an objective evaluation method, it has become important to adopt more objective ways of evaluating outcomes. ${ }^{16} \mathrm{Al}$ though quantitative facial analysis of standardized 2D preand postoperative photos is the yardstick by which most rhinoplasty results are judged, the continued development of digital imaging and computing technology has begun to offer a more precise evaluation of facial measurements after rhinoplasty. These tools provide an objective, accurate, and reliable system for quantifying the changes of the soft tissue of the nose that occur after surgery, and objectively measure rhinoplasty results. An appraisal of the literature on 3D surface imaging for rhinoplasty or other facial plastic surgery procedures has revealed several studies that demonstrate the accuracy and reproducibility of these techniques (-Table 2 ).

Honrado and colleagues assessed the changes in nasal measurements by comparing pre- and postoperative imaging in patients who received maxillomandibular surgery. ${ }^{32}$ Three-dimensional imaging was used to evaluate the nasal height change after hump reduction by van Heerbeek and colleagues. ${ }^{33}$ van Loon and his colleagues compared the paranasal volumes before and after surgery to assess the difference in swelling after percutaneous versus endonasal osteotomies. ${ }^{34}$ Another article by van Loon et al evaluated the symmetry of the lip and nose in patients with unilateral clefts after primary septoplasty and cleft lip repair. ${ }^{35}$ The same group of researchers applied 3D imaging to the evaluation of patients with clefts, measuring the volume of the cleft and noncleft sides of the nose after rhinoplasty. ${ }^{36}$ Simanca et al evaluated 3D changes of the nose and soft tissues of the lip in patients with unilateral clefts after presurgical nasoalveolar molding. ${ }^{37}$ Toriumi and Dixon provide a description of techniques used to assess rhinoplasty results with the overlay of before and after 3D images. ${ }^{16}$ 
Table 2 Publications on 3D surface imaging systems in facial plastic surgery

\begin{tabular}{|c|c|c|c|}
\hline Authors & Journal & Title & $\begin{array}{l}\text { Year, volume, and } \\
\text { page range }\end{array}$ \\
\hline van Loon et al & $\begin{array}{l}\text { Int J Oral } \\
\text { Maxillofac Surg }\end{array}$ & $\begin{array}{l}\text { Three-dimensional changes in nose and upper lip volume after } \\
\text { orthognathic surgery }\end{array}$ & 2015;44:83-89 \\
\hline Bared et al & $\begin{array}{l}\text { JAMA Facial Plast } \\
\text { Surg }\end{array}$ & $\begin{array}{l}\text { Lower lateral cartilage repositioning: objective analysis using } \\
\text { 3-dimensional imaging }\end{array}$ & $2014 ; 16: 261-267$ \\
\hline Tzou et al & $\begin{array}{l}\text { J Plast Reconstr } \\
\text { Aesthet Surg }\end{array}$ & Comparison of three-dimensional surface imaging systems & 2014;67:489-497 \\
\hline Dixon et al & Facial Plast Surg & $\begin{array}{l}\text { Three-dimensional evaluation of unilateral cleft rhinoplasty } \\
\text { results }\end{array}$ & 2013;29:106-115 \\
\hline Pallanch & $\begin{array}{l}\text { Facial Plast Surg Clin } \\
\text { North Am }\end{array}$ & $\begin{array}{l}\text { Introduction to 3D imaging technologies for the facial plastic } \\
\text { surgeon }\end{array}$ & 2011;19:xv-xvi \\
\hline Pallanch & $\begin{array}{l}\text { Facial Plast Surg Clin } \\
\text { North Am }\end{array}$ & 3D and the next dimension for facial plastic surgery & 2011;19:xix-xxi \\
\hline $\begin{array}{l}\text { Toriumi and } \\
\text { Dixon }\end{array}$ & $\begin{array}{l}\text { Facial Plast Surg Clin } \\
\text { North Am }\end{array}$ & $\begin{array}{l}\text { Assessment of rhinoplasty techniques by overlay of before-and- } \\
\text { after 3D images }\end{array}$ & $2011 ; 19: 711-723$ \\
\hline van Loon et al & Rhinology & $\begin{array}{l}\text { Postoperative volume increase of facial soft tissue after } \\
\text { percutaneous versus endonasal osteotomy technique in } \\
\text { rhinoplasty using 3D stereophotogrammetry }\end{array}$ & 2011;49:121-126 \\
\hline van Loon et al & Rhinology & $\begin{array}{l}\text { 3D stereophotogrammetric analysis of lip and nasal symmetry } \\
\text { after primary cheiloseptoplasty in complete unilateral cleft lip } \\
\text { repair }\end{array}$ & $2011 ; 49: 546-553$ \\
\hline Simanca et al & J Craniofac Surg & $\begin{array}{l}\text { Measuring progressive soft tissue change with nasoalveolar } \\
\text { molding using a three-dimensional system }\end{array}$ & $\begin{array}{l}2011 ; 22: \\
1622-1625\end{array}$ \\
\hline Tzou and Frey & $\begin{array}{l}\text { Facial Plast Surg Clin } \\
\text { North Am }\end{array}$ & Evolution of 3D surface imaging systems in facial plastic surgery & 2011;19:591-602 \\
\hline van Loon et al & $\begin{array}{l}\text { Int J Oral Maxillofac } \\
\text { Surg }\end{array}$ & $\begin{array}{l}\text { 3D Stereophotogrammetric assessment of pre- and } \\
\text { postoperative volumetric changes in the cleft lip and palate nose }\end{array}$ & 2010;39:534-540 \\
\hline $\begin{array}{l}\text { Moscatiello } \\
\text { et al }\end{array}$ & Aesthetic Plast Surg & Preoperative digital three-dimensional planning for rhinoplasty & $2010 ; 34: 232-238$ \\
\hline $\begin{array}{l}\text { van Heerbeek } \\
\text { et al }\end{array}$ & Rhinology & Three dimensional measurement of rhinoplasty results & 2009;47:121-125 \\
\hline Honrado et al & Arch Facial Plast Surg & $\begin{array}{l}\text { Quantitative assessment of nasal changes after maxillomandib- } \\
\text { ular surgery using a 3-dimensional digital imaging system }\end{array}$ & $2006 ; 8: 26-35$ \\
\hline Aldridge et al & Am J Med Genetics & $\begin{array}{l}\text { Precision and error of three-dimensional phenotypic measures } \\
\text { acquired from 3dMD photogrammetric images }\end{array}$ & $\begin{array}{l}2005 ; 138: \\
247-253\end{array}$ \\
\hline Lee & Arch Facial Plast Surg & $\begin{array}{l}\text { Three-dimensional photography and its application to facial } \\
\text { plastic surgery }\end{array}$ & 2004;6:410-414 \\
\hline $\begin{array}{l}\text { Honrado and } \\
\text { Larrabee }\end{array}$ & $\begin{array}{l}\text { Curr Opin } \\
\text { Otolaryngol Head } \\
\text { Neck Surg }\end{array}$ & Update in three-dimensional imaging in facial plastic surgery & $2004 ; 12: 327-331$ \\
\hline
\end{tabular}

Dixon and colleagues used 3D imaging software to assess the surgical changes of patients with unilateral clefts who underwent secondary rhinoplasty. ${ }^{38}$

The first study that analyzed nasal tip volumes in patients with bulbous tips is by Bared et al, who used 3D imaging software to demonstrate the changes in nasal tip volume after lower lateral cartilage repositioning. ${ }^{39}$ van Loon et al also investigated the influence of maxillary movement on the soft tissues of the nose and lip by measuring their 3D changes after surgery. ${ }^{40}$ Volumetric analysis is an exciting new capability offered by 3D imaging tools.

With 3D imaging and analysis, the ability to rotate the surface around and make measurements on it results in images that are more accurate and reproducible than with conventional photography. Not only is the surgeon able to match positions of pre- and postoperative images over time very precisely, but also he can overlay one on top of another and see what is moving forward and what is moving backward even at very subtle levels. The ability to track 3D changes in the postoperative nose with time is an additional advantage of 3D imaging application. ${ }^{16}$ The authors have demonstrated the capacity of the system to perform topographic measurements by calculating the topographic distance between two points along the contour of the nose. This is in contrast to the relative measurements arising from 2D images. Finally, 3D imaging can be used not only to objectify or 
measure results after rhinoplasty, but also to study whether the desired effects are long term to compare results between different rhinoplasty techniques, all in the interest of a successful outcome. Three-dimensional imaging and simulation is a new value that is changing yet again the way that doctors evaluate preoperatively and postoperatively their rhinoplasty patients.

\section{Disadvantages of 3D}

Three-dimensional imaging systems are significantly more expensive than their 2D predecessors, often costing thousands of dollars. ${ }^{41}$ However, with advancement of computer and imaging technology, it is expected that more affordable systems will be developed in the near future for standard clinical practice.

\section{The Future of 3D Applications in Rhinoplasty}

Today, the requirement to think and conceptualize in 3D has contributed to the emergence of facial sculpturing courses and workshops, where facial plastic surgeons engage into perceptual exercises in clay to do eye training, mental 3D imaging, and appreciate what is possible by any 3D manipulation. 42

One of the most promising innovations in biomedical science is $3 \mathrm{D}$ printing. Tactile models and their adoption in a variety of medical fields have shown that they can be very helpful for preoperative consultations with patients and as a real intraoperative $1: 1$ scale reference. ${ }^{43}$ Other authors emphasize that 3D-printed models translate preoperative imaging data into useful tools that may help surgeons both reduce operating room time and potentially improve surgical results. ${ }^{44}$ More recently, head and neck surgeons have used 3D printing to provide preoperative models for complex surgeries. As facial plastic surgery needs to fulfill the different demands from a diverse patient population, the application of tailored 3D printing will become indispensable. ${ }^{45}$ The use of 3D digital technology and printing to create templates for soft tissue reconstruction has also been described, although it is in its infancy. ${ }^{46}$ In the spirit of patient-specific individualized medicine, 3D printing may also have innovative clinical applications for personalized rhinoplasty. The possibility of using the patients' 3D images to print a 3D moldable model of the patients' face and nose would augment the ability to conceptualize the surgical steps for any given patient. At the same time, it would render patient consultations more effective and increase diagnostic quality.

The application of the 3D printing technique has even been extended from Biocell printing for 3D tissue/organ development to the creation of scaffold for tissue engineering and actual clinical application for various medical parts. In rhinoplasty, novel materials are required that can replace or complement conventional materials, including autologous tissue, and these methods can be the basis for applying tissue engineering techniques in rhinoplasty. ${ }^{45}$

It is clear that outcomes assessment has moved from the restricted evaluation of results with angles, ratios, and dis- tance measurements to the emerging era of objectively measuring results and demonstrating changes. With such a remarkable way of quantifying postoperative changes offered with $3 \mathrm{D}$ imaging, the rhinoplasty surgeon would be able to ultimately compare different approaches and technical subtleties to achieve the highest level of patient satisfaction and hence surgical success. Providing accuracy and objectivity in the evaluation of volumetric changes following rhinoplasty will open new avenues in the arena of outcomes research. In the future, there may be a role for correlating the degree of patient satisfaction to the amount of volume change assessed.

The potential wealth of information derived from 3D analyses of results of different rhinoplasty techniques is also substantial. Applying these analyses to large patient databases, surgeons can discover which techniques shorten procedure and anesthetic time, or increase the chances of success. ${ }^{47}$ Ultimately, these data can be used to increase the predictability of surgical results in rhinoplasty.

\section{Conclusion}

Facial plastic surgery is unique in that many of its advances are conceived in the industry, and not in the laboratory. This review demonstrates that $3 \mathrm{D}$ surface imaging is taking surgeons to a new level of communication with patients, surgical planning, and outcome evaluation. It will be shortsighted not to realize that there is a sea change upon us, reinforced largely by the advances and innovation in computing and imaging technology. There is no doubt that technology and innovation can help us improve the care of our patients. But for now we have to endeavor a closer collaboration between medicine, academia, and industry to provide more evidence that would allow us to introduce the benefits of 3D technology into clinical practice at a reasonable cost for a sustainable health care system. We are in the early stages of many future articles objectifying the difference that 3D technology can make in outcomes, such as surgeon satisfaction, patient satisfaction, operative results, and operative time and costs. ${ }^{47}$

For the rhinoplasty surgeon, patient satisfaction will continue to remain one of the most important parameters of success. The use of 3D imaging serves as a tangible representation of a certain caliber in the management of the rhinoplasty patient from the preoperative evaluation all the way to the postoperative assessment. The importance of tools like 3D imaging will only be increasing in the future, enhancing patient's centered care, outcomes-oriented research, and a transparency-driven health care philosophy. We look to the future with optimism as we move forward into the world of personalized medicine.

\section{References}

1 Werther JR, Freeman JP. Changes in nasal tip projection and rotation after septorhinoplasty: a cephalometric analysis. J Oral Maxillofac Surg 1998;56(6):728-732, discussion 733

2 Byrd HS, Hobar PC. Rhinoplasty: a practical guide for surgical planning. Plast Reconstr Surg 1993;91(4):642-654, discussion $655-656$ 
3 Ingels K, Orhan KS. Measurement of preoperative and postoperative nasal tip projection and rotation. Arch Facial Plast Surg 2006; 8(6):411-415

4 Nkenke E, Langer A, Laboureux X, et al. Validation of in vivo assessment of facial soft-tissue volume changes and clinical application in midfacial distraction: a technical report. Plast Reconstr Surg 2003;112(2):367-380

5 Henderson JL, Larrabee WF Jr, Krieger BD. Photographic standards for facial plastic surgery. Arch Facial Plast Surg 2005;7(5):331-333

6 Swamy RS, Sykes JM, Most SP. Principles of photography in rhinoplasty for the digital photographer. Clin Plast Surg 2010; 37(2):213-221

7 Becker DG, Tardy ME Jr. Standardized photography in facial plastic surgery: pearls and pitfalls. Facial Plast Surg 1999;15(2):93-99

8 Shah AR, Dayan SH, Hamilton GS III. Pitfalls of photography for facial resurfacing and rejuvenation procedures. Facial Plast Surg 2005;21(2):154-161

9 Da Silveira AC, Daw JL Jr, Kusnoto B, Evans C, Cohen M. Craniofacial applications of three-dimensional laser surface scanning. J Craniofac Surg 2003;14(4):449-456

10 Alves PVM, Zhao L, Patel PK, Bolognese AM. Three-dimensional facial surface analysis of patients with skeletal malocclusion. J Craniofac Surg 2009;20(2):290-296

11 Honrado CP, Larrabee WF Jr. Update in three-dimensional imaging in facial plastic surgery. Curr Opin Otolaryngol Head Neck Surg 2004;12(4):327-331

12 Tzou C-HJ, Frey M. Evolution of 3D surface imaging systems in facial plastic surgery. Facial Plast Surg Clin North Am 2011;19(4): 591-602, vii

13 Hajeer MY, Ayoub AF, Millett DT, Bock M, Siebert JP. Threedimensional imaging in orthognathic surgery: the clinical application of a new method. Int J Adult Orthodon Orthognath Surg 2002;17(4):318-330

14 Hell B. 3D sonography. Int J Oral Maxillofac Surg 1995;24(1, Pt 2): 84-89

15 Largo RD, Wettstein R, Fulco I, et al. Three-dimensional laser surface scanning in rhinosurgery. Facial Plast Surg 2013;29(2):116-120

16 Toriumi DM, Dixon TK. Assessment of rhinoplasty techniques by overlay of before-and-after 3D images. Facial Plast Surg Clin North Am 2011;19(4):711-723, ix

17 Yuen K, Kawakami S, Ogawara T, Inokuchi I, Maeta M, Masuda Y. Evaluation of facial palsy by Moiré topography. Eur Arch Otorhinolaryngol 1994;(Dec):S541-S544

18 Kawai T, Natsume N, Shibata H, Yamamoto T. Three-dimensional analysis of facial morphology using moiré stripes. Part II. Analysis of normal adults. Int J Oral Maxillofac Surg 1990; 19(6):359-362

19 Tzou C-HJ, Artner NM, Pona I, et al. Comparison of three-dimensional surface-imaging systems. J Plast Reconstr Aesthet Surg 2014;67(4):489-497

20 Beard LF, Burke PH. Evolution of a system of stereophotogrammetry for the study of facial morphology. Med Biol Illus 1967;17(1):20-25

21 Aldridge K, Boyadjiev SA, Capone GT, DeLeon VB, Richtsmeier JT. Precision and error of three-dimensional phenotypic measures acquired from 3dMD photogrammetric images. Am J Med Genet A 2005;138A(3):247-253

22 Ayoub A, Garrahy A, Hood C, et al. Validation of a vision-based, three-dimensional facial imaging system. Cleft Palate Craniofac J 2003;40(5):523-529

23 Weinberg SM, Scott NM, Neiswanger K, Brandon CA, Marazita ML Digital three-dimensional photogrammetry: evaluation of anthropometric precision and accuracy using a Genex 3D camera system. Cleft Palate Craniofac J 2004;41(5):507-518

24 Wong JY, Oh AK, Ohta E, et al. Validity and reliability of craniofacial anthropometric measurement of 3D digital photogrammetric images. Cleft Palate Craniofac J 2008;45(3):232-239

25 Moscatiello F, Herrero Jover J, González Ballester MA, Carreño Hernández E, Piombino P, Califano L. Preoperative digital three- dimensional planning for rhinoplasty. Aesthetic Plast Surg 2010; 34(2):232-238

26 Constantinides $M$. The rhinoplasty consultation and the business of rhinoplasty. Facial Plast Surg Clin North Am 2009;17(1):1-5, v

27 Steiger JD. The rhinoplasty consult. Facial Plast Surg 2011;27(5): 393-396

28 Gerstle TL, Ibrahim AMS, Kim PS, Lee BT, Lin SJ. A plastic surgery application in evolution: three-dimensional printing. Plast Reconstr Surg 2014;133(2):446-451

29 Pallanch J. Introduction to 3D imaging technologies for the facial plastic surgeon. Facial Plast Surg Clin North Am 2011;19(4): $\mathrm{xv}-\mathrm{xvi}$, vii

30 Chen HH, Javadi P, Daines SM, Williams EF III. Quantitative assessment of the longevity of poly-L-lactic acid as a volumizing filler using 3-dimensional photography. JAMA Facial Plast Surg 2015;17(1):39-43

31 Most SP, Alsarraf R, Larrabee WF Jr. Outcomes of facial cosmetic procedures. Facial Plast Surg 2002;18(2):119-124

32 Honrado CP, Lee S, Bloomquist DS, Larrabee WF Jr. Quantitative assessment of nasal changes after maxillomandibular surgery using a 3-dimensional digital imaging system. Arch Facial Plast Surg 2006;8(1):26-35

33 van Heerbeek N, Ingels KJAO, van Loon B, Plooij JM, Bergé SJ. Three dimensional measurement of rhinoplasty results. Rhinology 2009;47(2):121-125

34 van Loon B, van Heerbeek N, Maal TJJ, et al. Postoperative volume increase of facial soft tissue after percutaneous versus endonasal osteotomy technique in rhinoplasty using 3D stereophotogrammetry. Rhinology 2011;49(1):121-126

35 van Loon B, Reddy SG, van Heerbeek N, et al. 3D stereophotogrammetric analysis of lip and nasal symmetry after primary cheiloseptoplasty in complete unilateral cleft lip repair. Rhinology 2011;49(5):546-553

36 van Loon B, Maal TJ, Plooij JM, et al. 3D Stereophotogrammetric assessment of pre- and postoperative volumetric changes in the cleft lip and palate nose. Int J Oral Maxillofac Surg 2010;39(6): 534-540

37 Simanca E, Morris D, Zhao L, Reisberg D, Viana G. Measuring progressive soft tissue change with nasoalveolar molding using a three-dimensional system. J Craniofac Surg 2011;22(5): $1622-1625$

38 Dixon TK, Caughlin BP, Munaretto N, Toriumi DM. Three-dimensional evaluation of unilateral cleft rhinoplasty results. Facial Plast Surg 2013;29(2):106-115

39 Bared A, Rashan A, Caughlin BP, Toriumi DM. Lower lateral cartilage repositioning: objective analysis using 3-dimensional imaging. JAMA Facial Plast Surg 2014;16(4):261-267

40 van Loon B, van Heerbeek N, Bierenbroodspot F, et al. Threedimensional changes in nose and upper lip volume after orthognathic surgery. Int J Oral Maxillofac Surg 2015;44(1):83-89

41 Lee $S$. Three-dimensional photography and its application to facial plastic surgery. Arch Fac Plast Surg 2004;6:410-414

42 Cingi C, Oghan F. Teaching 3D sculpting to facial plastic surgeons. Facial Plast Surg Clin North Am 2011;19(4):603-614, viii

43 Choi JW, Kim N. Clinical application of three-dimensional printing technology in craniofacial plastic surgery. Arch Plast Surg 2015; 42(3):267-277

44 Michalski MH, Ross JS. The shape of things to come: 3D printing in medicine. JAMA 2014;312(21):2213-2214

$45 \mathrm{Kim}$ YS, Shin YS, Park Y, et al. The application of three-dimensional printing in animal model of augmentation rhinoplasty. Ann Biomed Eng 2015;43(9):2153-2162

46 Lindsay RW, Herberg M, Liacouras P. The use of three-dimensional digital technology and additive manufacturing to create templates for soft-tissue reconstruction. Plast Reconstr Surg 2012;130(4): 629e-631e

47 Pallanch J. 3D and the next dimension for facial plastic surgery Facial Plast Surg Clin North Am 2011;19(4):xix-xxi 